\title{
A Heated Electrospray Source for Mass Spectrometry of Analytes from Aqueous Solutions
}

\author{
Michael G. Ikonomou* and Paul Kebarle \\ Chemistry Department, University of Alberta, Edmonton, Canada
}

\begin{abstract}
An electrospray interface is described that provides high sensitivity and signal stability for mass spectrometric detection of analytes in solvents with high water content including $100 \%$ water. The electrospray capillary tip section is heated close to the boiling point of the solvent. An approximately $20^{\circ} \mathrm{C}$ hotter airstream, with flow coaxial to the electrospray tip and codirectional to the electrospray, is also used. With this arrangement, the analyte signal sensitivity and stability obtained with neat water is equal to that obtained with neat methanol. The heated electrospray also affords the use of a wide range of flow rates: 1-100 $\mu \mathrm{L} / \mathrm{min}$, (I Am Soc Mass Spectrom 1994, 5, 791-799)
\end{abstract}

$\mathrm{E}$ lectrospray (ES) mass spectrometry with neat water as solvent is more difficult when compared to ES that involves solvents like methanol, ethanol, and acetonitrile. When neat water is used, the analyte signal observed is relatively very unstable and the ion intensity at a given analyte concentration is low. Electrospray of aqueous solutions is very desirable particularly in reverse phase high-performance liquid chromatography (HPLC), where to obtain reasonable retention times one has to work with a mobile phase in which the analyte ions are very soluble. This in practice means solvents in which water is the major component. The same is true also for capillary electrophoresis, where for similar reasons water is the normal solvent used.

Smith et al. [1] found a method with which they could electrospray aqueous solutions. In their "liquid sheath electrode" they combine, at the capillary tip, an outer liquid sheath of methanol with the inner aqueous flow that emerges from the capillary. Thus, the solvent sprayed is actually a water-methanol mixture that is amenable to ES. Although the method appears to work well, it still is desirable to develop a method with which aqueous solutions can be electrosprayed without premixing with methanol.

One of the factors that leads to poor performance for water as solvent is well understood. Smith [2] has shown that the electric field $E_{\text {on }}$ required for the onset of electrospray is given by

$$
E_{o n}=\left(2 \gamma \cos \theta / \varepsilon_{0} r_{c}\right)^{1 / 2}
$$

Address reprint requests to Professor Paul Kebarle, Chemistry De partment, University of Alberta, Edmonton, AB, Canada T6G 2G:2. - Present address: Institute of Ocean Science, P.O. Box 6000, 9860 West Saanich Road, Sidney, B.C. V8L 4B2. where $\gamma$ is the surface tension, $\theta=49^{\circ}$ is the half angle of the liquid cone (Taylor cone) at the capillary tip and $\varepsilon_{0}$ and $r_{c}$ are the permittivity of vacuum and the radius of the capillary. Because water has a surface tension $\left(\gamma=0.073 \mathrm{~N} \mathrm{~m}^{-2}\right)$ that is more than three times higher than that of methanol $\left(\gamma=0.023 \mathrm{~N} \mathrm{~m}^{-2}\right)$, the $E_{\text {on }}$ for water is close to two times higher. Generally, for a stable spray one needs a potential that is some 200-300 V above the onset potential, and for water the potential that would have led to stable spray causes electrical breakdown in the ambient gas-air [2, 3]. Gas-phase ions then are formed not only by the ES process, but also by gas-phase ionization due to corona discharge. Although generally it is easy to distinguish with the mass spectrometer between ES ions and discharge ions [3], the presence of electric discharge, which can be intermittent in this voltage range, leads to an instability of the ES-derived analyte signal. The analyte signal is also strongly depressed when a discharge current approaching approximately $0.8 \mu \mathrm{A}$ or higher is present [3].

The discharge can be suppressed by the application of $\mathrm{SF}_{6}$ gas flow around the ES capillary tip [3]. Suppression of the discharge with $\mathrm{SF}_{6}$ was found to lead to stable analyte signals and an increase of the analyte ion intensity. However, the sensitivity still remained lower by a factor of about 4 relative to that observed with methanol, even though the total capillary current $I_{c}$ was essentially the same when water or methanol were used as solvents [3].

The lower yield of gas-phase ions from the charged droplets for water relative to methanol could be due to various factors:

1. Larger droplets for a given charge could be formed when water is sprayed. The initial size of the 
droplets is one of the most important parameters. The charged droplets should not only be close to the Rayleigh limit, but also very small. Under these conditions droplets small enough to lead to gasphase ions may be generated only after a few Rayleigh explosions $[4,5]$.

2. For droplets of equal radius and equal charge, the rate of solvent evaporation could be slower and thus the time required to reduce the droplet size to that where gas-phase ion emission occurs could be longer for water.

3. For droplets of sufficiently small size so that gasphase ion emission can occur, ion emission could be slower out of water relative to methanol.

Fernandez de la Mora [6] recently proposed that the relative size of droplets can be predicted

$$
d \alpha\left(\rho Q^{2} / \gamma\right)^{1 / 3}
$$

where $d$ is the droplet diameter, $\rho$ is the density of the solvent, and $Q$ is the flow rate, and this provides an answer to question 1 . According to eq 2 the ratio of droplet size at the same flow rate should be

$$
\frac{d(\mathrm{MeOH})}{d(\mathrm{HOH})} \approx\left(\frac{0.8}{1} \times \frac{0.073}{0.023}\right)^{1 / 2}=1.36
$$

Thus according to eq $2, \mathrm{MeOH}$ should lead to somewhat larger droplets and this means that factor 1 could not be responsible for the lower ion yield from water.

Regarding question 2, a slower droplet evaporation for water relative to methanol can be expected. Small droplets, with diameters of a few micrometers, from volatile liquids such as water or methanol are expected to shrink by evaporation at a rate that is controlled by the surface evaporation limit law [7], and for these conditions one expects a rate of shrinkage that is proportional to the vapor pressure of the liquid $[5,7]$. The vapor pressures at $20^{\circ} \mathrm{C}$ are: $p(\mathrm{MeOH}) \approx 100$ torr and $p(\mathrm{HOH}) \approx 20$ torr. On this basis one would expect that $\mathrm{MeOH}$ droplets initially of equal size will reduce their size much more rapidly than water droplets.

In our previous work $[3,8]$ we examined question 3 on the basis of the model of Iribarne and Thomson [9] "ion evaporation" out of very small droplets $\left(r<10^{-2}\right.$ $\mu \mathrm{m}$ ) and came to the conclusion that the rate of ion evaporation will be higher for methanol relative to water when droplets of the same charge and radius are compared. However, the Iribarne-Thomson theory may not hold. The recent findings [4] that the charged droplet fission occurs through emission of a stream of some 20 highly charged and small offspring droplets that carry off only approximately $2 \%$ of the mass but
$15 \%$ of the charge of the parent droplet, and other considerations [5] provide considerable support for a rival theory [10] according to which the gas phase ions are formed by the evaporation of very small droplets ( $\sim 1 \mathrm{~nm}$ ) that contain only one ion.

It appears therefore that factor 2 is the main reason for the lower gas phase ion yield out of water droplets. On that basis one might expect that heating the droplets will lead to better performance when water is used.

The successful heated interface developed in our laboratory for the expressed purpose of spraying water is described in subsequent sections. Here we wish to emphasize that the ultimately successful design was based to a great extent on empirical optimization rather than on theoretical reasoning. As will be discussed below, the empirically optimized heated electrospray interface $(E S H)$ provides superior performance not only because a heated gas stream leads to faster evaporation of the droplets, but also because of the empirical discovery that a much finer spray, that is, much smaller droplets, can be obtained by heating the solution to near the boiling point of the solvent $\left(\sim 100^{\circ} \mathrm{C}\right)$.

Other research groups [11-15] have reported the use of heat to improve performance. However, the use of heat was not introduced specifically for ES of water. Fenn and co-workers [11] reported the use of drying. gas $\left(\mathrm{N}_{2}\right)$ heated to $330-350 \mathrm{~K}$. Comparative experiments that demonstrate the utility of this procedure were not reported.

Smith et al. [12] used heated nitrogen (interface) gas at $70^{\circ} \mathrm{C}$ flowing in a counter current to the spray for the desolvation of the gas-phase ions. The purpose of these experiments was obviously different from that of the present work.

Chait and co-workers [13] used a heated capillary tube $\left(80-100^{\circ} \mathrm{C}\right)$ to transfer ES from atmospheric pressure to the vacuum system of the mass spectrometer. The purpose was to desolvate the droplets and gasphase ions. The solvent used was a 50:50 methanolwater mixture. A capillary temperature of $85^{\circ} \mathrm{C}$ was found to maximize the protonated peptide signals. Experiments with other solvent mixtures and neat water were not reported.

Siu and co-workers [14] and Chait and co-workers [15] have used heating of the electrospray capillary and acidified aqueous protein solutions to induce denaturation of the protein. The denaturation manifests itself by an increased degree of protonation in the observed mass spectra $[14,15]$. No clear-cut information on increases of sensitivity or signal stability and no optimization of temperature for this purpose is reported in this work.

Lee and Henion [16] developed a heated electrospray interface where the electrospray capillary is heated to temperatures close to the boiling point of the solvent. The aim of their work was to provide an ES generator that can operate at very high flow rates up to $500 \mu \mathrm{L} / \mathrm{min}$. The capability of the device with regard 
to high aqueous content solutions was not examined at any flow rate.

As will become evident in subsequent sections, the present heated ES interface is different in design and purpose from those used in previous work [11-13, 16]. The present device incorporates (1) directional focusing by using a mild air stream coaxial and codirectional to the ES capillary; (2) differential heating that allows the air stream to be some $20{ }^{\circ} \mathrm{C}$ hotter than the ES capillary; (3) high sensitivity for analytes elcctrosprayed from aqueous solutions. The performance for aqueous solutions is documented by comparisons with ES data obtained without heating and with other solvents (methanol).

\section{Experimental}

\section{Apparatus}

The heated electrospray generator (ESH; Figure 1), was mounted inside the atmospheric plenum chamber of a Sciex (Thornhill, Ontario) TAGA 6000E triple quadrupole mass spectrometer [17]. The use of the TAGA $6000 \mathrm{E}$ for ES work in our laboratory has been described elsewhere [8, 18]; here we consider only the relevant features. The mounting of the ESH permits motion in three $(x, y, z)$ directions. The applied potentials were ES generator, $4-6 \mathrm{kV}$; counterelectrode, that is, top plate of interface chamber, $650 \mathrm{~V}$; bottom plate of interface chamber and orifice to vacuum, $60 \mathrm{~V}$.

The charged droplets produced by the ESH, whose tip is approximately $3 \mathrm{~cm}$ from the interface plate, drift downfield toward the interface plate. The droplet current leaving the capillary can be measured $[8,18]$ and will be called $I_{c}$. Under ideal circumstances most of the charge on the droplets becomes converted to gasphase ions before the droplets reach the interface plate. A fraction of the ions and charged droplets that enter the interface chamber through the 3.4-mm-diameter orifice in the interface plate drift through ultrapure $\mathrm{N}_{2}$ gas at $1 \mathrm{~atm}$ toward the bottom plate of the interface chamber. The ions that enter the interface chamber are solvated by several solvent molecules (per charge) and desolvation (declustering) down to one or two solvent

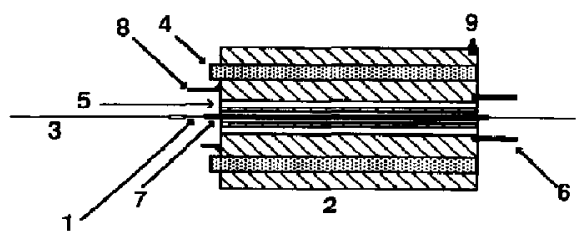

Figure 1. Enlarged view of the heated ES assembly: 1, stainless steel electrospray capillary; 2 , heated copper block; 3 , silica tubing supplying solution; 4 , cartridge heaters (70W); 5, air flow channels; 6, air flow guide; 7, fused silica coaxial insulating tubes; 8 , heated ES assembly holder; 9, thermocouple. molecules occurs in the dry nitrogen $[8,18]$. Ions that arrive near the central $115-\mu \mathrm{m}$ orifice, located on a foil on the bottom interface plate, are entrained by the gas flow into the vacuum of the mass spectrometer.

The ES capillary ( 1 see Figure 1) is of stainless steel (ss) $0.2 \mathrm{~mm}$ o.d., $0.1 \mathrm{~mm}$ i.d., and $9 \mathrm{~cm}$ long. Two coaxial silica tubes (7) that are 1.5 and $3 \mathrm{~mm}$ o.d. thermally shield the capillary from the heated copper block (2). This arrangement keeps the ES capillary some $20-25^{\circ} \mathrm{C}$ below the block temperature. The cylindrical Cu block, which is $4.5 \mathrm{~cm}$ long, has four channels (4) that hold 70-W cartridge heaters and there are also six air flow channels (5) through which $0.5-\mathrm{L} / \mathrm{s}$ air enters the plenum chamber. The heated air after passing through channels (5) is guided around the ES capillary tip by means of a short 1.5-cm-o.d. ss tube (6).

The temperature of the copper block was monitored with a thermocouple (9) attached to the block surface. All temperatures given in Figures 2-5 were obtained with this thermocouple.

The analyte solutions were transported from the syringe pump to the ES capillary via $50-\mu \mathrm{m}$ fused silica tubing. The solution flow rate was $10 \mu \mathrm{L} / \mathrm{min}$ in all experiments unless otherwise mentioned.

Mass analysis was obtained with the third quadrupole $Q_{3}$, while $Q_{1}$ and $Q_{2}$ were operated in the rf-only total ion mode. The analytes were protonated bases $\mathrm{BH}^{+}$, such as obtained by dissolving the salts, generally $\mathrm{BHCl}$, into the solvent.

The gas-phase ions $\mathrm{BH}^{+}$and $\mathrm{BH}^{+}(\mathrm{SL})$, where SL are solvent molecules passing through the orifice into the vacuum, are in a cold supersonic jet and may experience growth to $\mathrm{BH}^{+}(\mathrm{SL})_{n}$. To prevent this, suitable accelerating potentials were applied to electrodes in the vacuum region, which lead to collisional activation of the ions and declustering to $\mathrm{BH}^{+}$.

\section{Optimization of Parameters}

Attempts were made to optimize several parameters. The optimization criteria used were maximum $\mathrm{BH}^{+}$ ion intensity and maximum ion signal stability. The following variables were examined: The effect of size and geometry of tube 6 (Figure 1), which directs the heated air flow over the capillary; the distance of the capillary tip beyond the air flow tube (6); the distance between the capillary tip and interface plate (4); the potential $V_{c}$ applied to capillary 1 ; the $C u$ block potential $V_{\mathrm{cu}}$; the thickness of thermal insulation (7) between Cu block 2 and capillary 1. The optimized dimensional and structural parameters were given in the preceding section. The optimized temperatures are considered in Results and Discussion.

\section{The High Potential of the ES Capillary}

In the present and previous work we operated with a capillary tip to counterelectrode potential of approxi- 

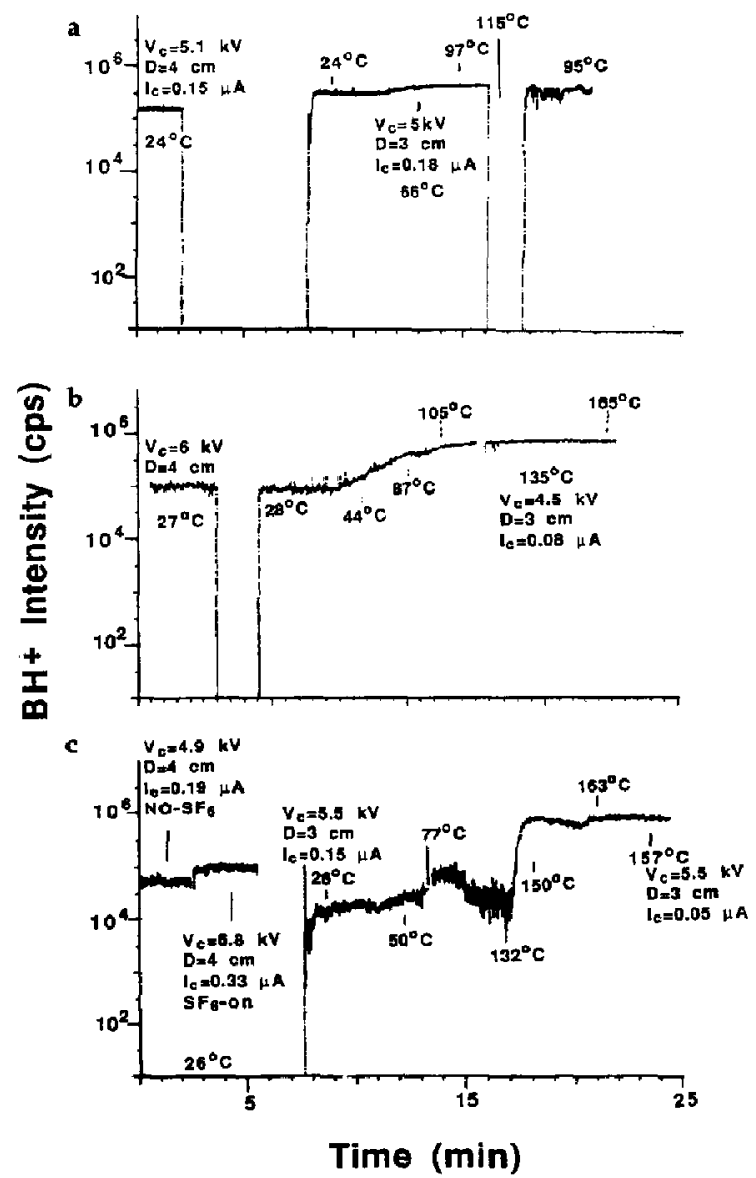

Figure 2. Single ion trace of $\mathrm{BH}^{+}$analyte ion intensity, $[\mathrm{BHCl}]$ $=10^{-5} \mathrm{~mol} / \mathrm{L}, \mathrm{B}$ is cocaine, for various spray conditions. (a) Solvent, $100 \% \mathrm{MeOH} ; 0-2 \mathrm{~min}$ trace with conventional ES capillary; 8-16-min trace with heated $\mathrm{ES}$ at indicated block temperatures, $I_{c}=0.18 \mu \mathrm{A}$. (b) Solvent, $50: 50 \mathrm{MeOH} / \mathrm{H}_{2} \mathrm{O}$; $0-3 \mathrm{~min}$ with conventional ES, 4-20 min with heated ES at indicated copper block temperatures. (c) Solvent, $100 \% \mathrm{H}_{2} \mathrm{O} ; 0-2.5 \mathrm{~min}$ with $\mathrm{ES} ; 2.5-5 \mathrm{~min} \mathrm{ES}$ with $\mathrm{SF}_{6}$ at $0.4 \mathrm{~L} / \mathrm{min} ; 7-25$ minutes with heated ES at indicated temperatures, $I_{\mathrm{c}}=0.05 \mu \mathrm{A}$ at $157^{\circ} \mathrm{C}$. Voltage applied to the ES capillary is indicated in each part of the figure.

mately $4 \mathrm{kV}$, which is close to $2 \mathrm{kV}$ higher than that used by other ES-mass spectrometry practitioners. However the distances used by us between tip and counterelectrode $(3-4 \mathrm{~cm})$ are also larger than those generally used (approximately $1 \mathrm{~cm}$ ). The high capillary potential used by us does not mean that our system is more prone to electric discharges. The production of a good spray depends on the electric field at the capillary tip and not on the potential, see for example eq 1 . The field $E$ in our experiments is probably very close to that present in the devices used by others. We use larger capillary to counterelectrode distances to minimize "flooding" of the interface chamber by unevaporated larger droplets. The same

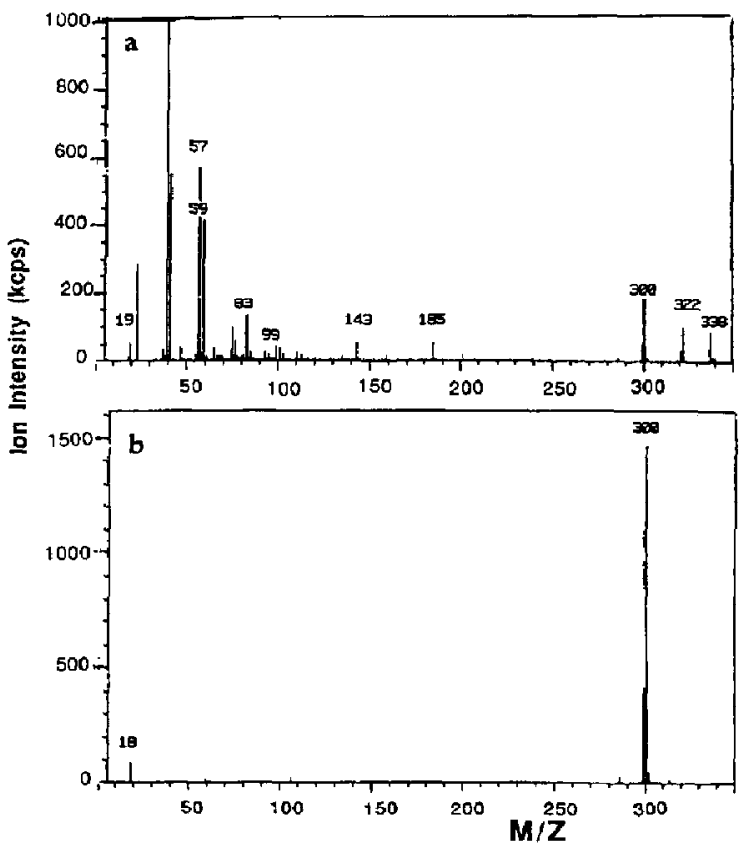

Figure 3. Mass spectra obtained with capillary tip at $5.3 \mathrm{kV}$ and $10^{-5}-\mathrm{mol} / \mathrm{L}$ solution of codeine $\mathrm{HCl}$ in $100 \%$ water at $10-\mu \mathrm{L} / \mathrm{min}$ flow rate. $m / z 300$ corresponds to protonated codeine $\mathrm{BH}^{+}$. (a) Spectrum obtained with ES capillary and room temperature. Peaks at $m / z 19$ and 37 due to $\mathrm{H}_{3} \mathrm{O}^{+}$and $\mathrm{H}_{2} \mathrm{O}^{+} \mathrm{H}_{2} \mathrm{O}$ indicate the presence of electric discharge. Peaks at $m / z 23,41$, and 59 due to $\mathrm{Na}^{+}\left(\mathrm{H}_{2} \mathrm{O}\right)_{n}$, peaks at $m / z 39,57$, and 75 due to $\mathrm{K}^{+}\left(\mathrm{H}_{2} \mathrm{O}\right)_{n,}$ and peaks at $m / z 322$ and 338 due to $\mathrm{BNa}^{+}$and $\mathrm{BK}^{+}$are due to $\mathrm{Na}^{+}$and $\mathrm{K}^{+}$impurities in solution. (b) Superclean spectrum obtained with the same solution and ESH at a block temperature $\sim 150^{\circ} \mathrm{C}$.

effect can be achieved by large offsets in the axial alignment between the capillary and the ion sampling orifice. Such an offset allows shorter capillary to counterelectrode distances to be used.

\section{Results and Discussion}

\section{Performance of the Heat Assisted Electrospray}

The ion intensity trace of the analyte ion $\mathrm{BH}^{+}$obtained from $\mathrm{ES}$ of $10^{-5}-\mathrm{mol} / \mathrm{L} \mathrm{BHCl}$ in methanol, where $\mathrm{B}$ is cocaine, is shown in Figure $2 \mathrm{a}$. The trace at short time was obtained with a conventional ES capillary that has dimensions identical to the heat-assisted capillary shown in Figure 1, but without the heater block and air stream. The $\mathrm{BH}^{+}$trace for the ES capillary was obtained for optimized parameters $\left(D=4 \mathrm{~cm}, V_{c}=6\right.$ $\mathrm{kV}$, and off- $X=1.5 \mathrm{~cm}$ ), where $D$ gives the distance from the capillary tip to the interface plate, $V_{c}$ is the capillary potential, and off- $X$ is the off-axis distance between the capillary axis and the orifice of the interface plate.

The $\mathrm{BH}^{+}$ion trace after $8 \mathrm{~min}$ shown in Figure $2 \mathrm{a}$ was obtained with the ESH at different block tempera- 

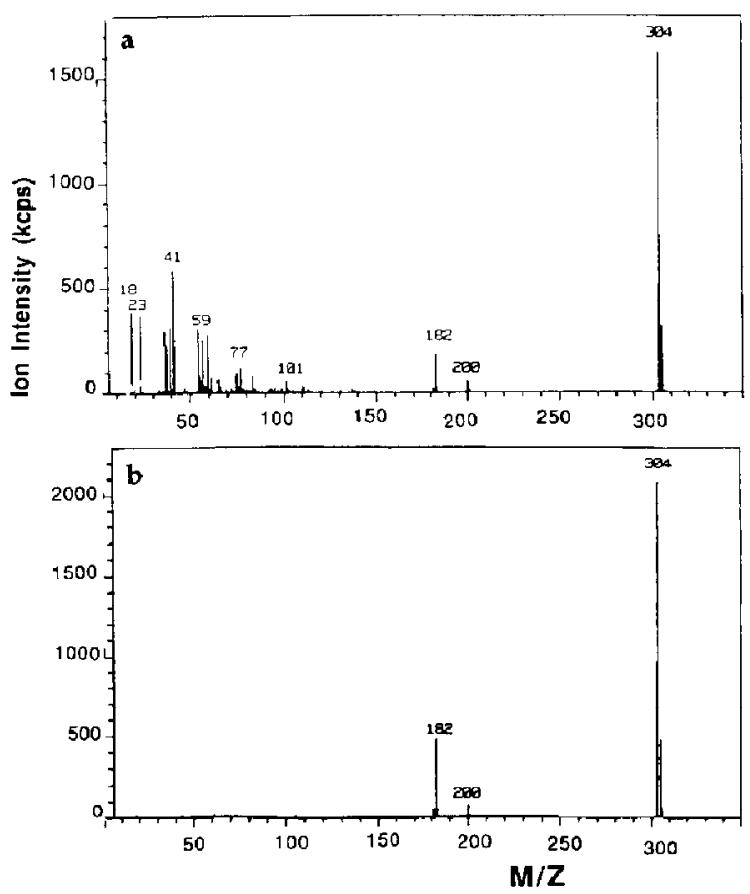

Figure 4. Comparison between normal and superclean ESH mass spectra obtained with the same solution $10^{-5}-\mathrm{mol} / \mathrm{L} \mathrm{co}$ caine $\mathrm{HCl}$ in $100 \%$ water, and $146{ }^{\circ} \mathrm{C}$ block temperature. (a) Normal spectrum in which substantial intensities due to impurity ions, mostly $\mathrm{Na}^{\prime}\left(\mathrm{H}_{2} \mathrm{O}\right)_{n}$, present in the solution, are observed. (b) Ultraclean spectrum obtained after fine tuning of the temperature $\left(\sim 160^{\circ} \mathrm{C}\right)$.

tures. The $\mathrm{BH}^{+}$intensity with ESH is higher by a factor of approximately 2 even when heating is not applied $\left(24^{\circ} \mathrm{C}\right)$. We attribute the higher signal to a directional "focusing" effect of the air flow. The directed flow, which is coaxial to the capillary, entrains the spray and reduces its angular divergence. It should be noted that the air flow velocity in the capillary tip region is not high enough to cause nebulization. Intensity increases by a factor of 2-3 were also observed for $\mathrm{BH}^{+}$, where $\mathrm{B}$ was codeine, tyrosine, inosine, adenosine, and bradykinin, where both $\mathrm{BH}^{+}$and $\left(\mathrm{BH}_{2}\right)^{2+}$ increased by a similar factor.

The application of heat increases the $\mathrm{BH}^{+}$signal somewhat, and a maximum is reached at $\sim 97^{\circ} \mathrm{C}$ block temperature (Figure 2a). Above this temperature, vapor was seen to escape from the capillary, an indication that the methanol was boiling. The current owing to charged droplets leaving the capillary $\left(I_{c}\right)$ as well as the mass-analyzed current $\mathrm{BH}^{+}$go to zero under these conditions; see the trace for $\mathrm{BH}^{+}$at $16 \mathrm{~min}$.

The $\mathrm{BH}^{+}$intensity trace when the solvent was a 50:50 mixture of methanol and water, is shown in Figure $2 \mathrm{~b}$. The trace at short times was obtained with the optimized ES capillary. The increase of $\mathrm{BH}^{+}$intensity with temperature, obtained with the ESH, is very much larger, by a factor of approximately 10 at the

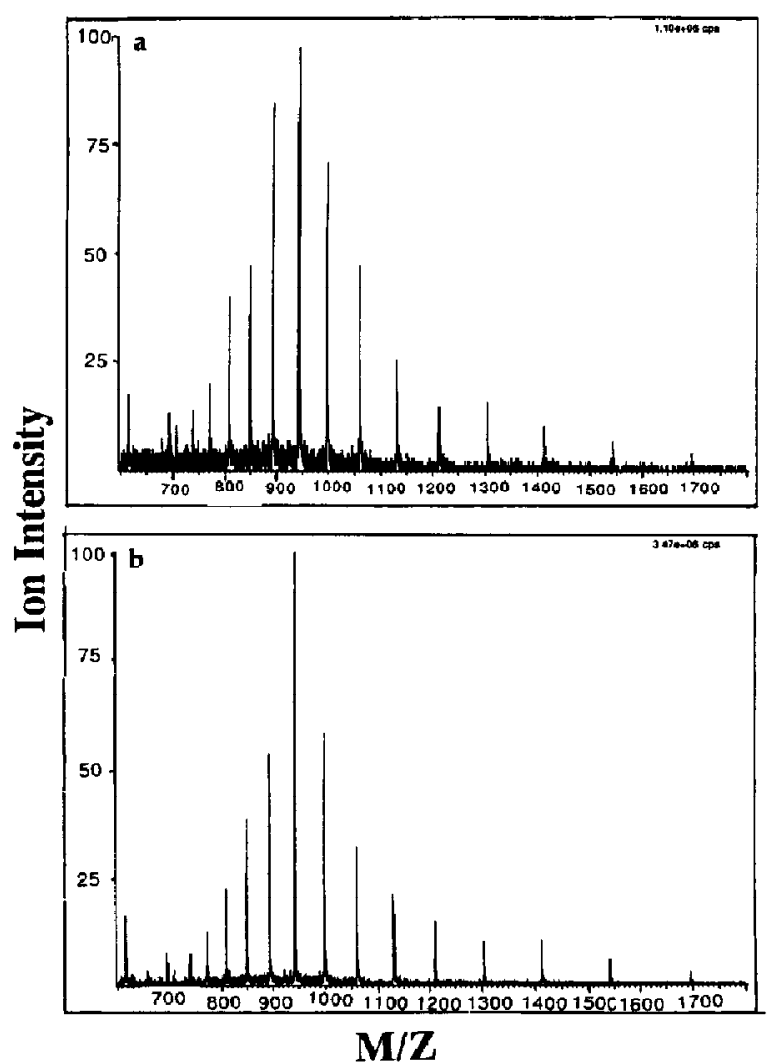

Figure 5. Mass spectra of myoglobin (horse's heart) obtained with $2.4 \times 10^{-6}-\mathrm{mol} / \mathrm{L}$ solution in $100 \%$ water with $0.1 \%$ trifluoro acetic acid at a flow rate of $20 \mu \mathrm{L} / \mathrm{min}$. (a) Spectrum obtained with the ion spray interface at $30{ }^{\circ} \mathrm{C}$. (b) Spectrum obtained with heated ES interface at a block temperature of 148 ${ }^{\circ} \mathrm{C}$. The intensity of the highest peak is $1.1 \times 10^{6} \mathrm{cps}$ in (a), and $3.5 \times 10^{6} \mathrm{cps}$ in (b).

optimum block temperature $135^{\circ} \mathrm{C}$, than was the case for neat methanol. It is important to note also the excellent signal stability evident from the $\mathrm{BH}^{+}$trace at higher temperatures.

The $\mathrm{BH}^{+}$intensity obtained with $100 \%$ water is shown in Figure 2c. The trace at short times was obtained with the conventional ES capillary. To avoid a strong corona discharge, the capillary potential was kept relatively low; $V_{c}=4.9 \mathrm{kV}$. A higher intensity is obtained at higher $V_{c}$ and $\mathrm{SF}_{6}$ gas flow. The capillary used in this experiment has an axial outer tube carrying $\mathrm{SF}_{6}$ gas [3]. The application of $\mathrm{SF}_{6}$ flow at 0.4 $\mathrm{L} /$ min allows a $V_{\mathrm{c}}=6.8 \mathrm{kV}$ to be used. The $\mathrm{BH}^{+}$ signal stability is also better with $\mathrm{SF}_{6}$. For more detailed comparisons, see [3]. By far the best conditions are obtained with the ESH. Intermediate block temperatures, $30-130^{\circ} \mathrm{C}$, do not lead to a stable signal, see Figure 2C. From 135 to $160^{\circ} \mathrm{C}$ a very stable signal is obtained both with regard to short and long time-constant fluctuations. The $\mathrm{BH}^{+}$signal at this intensity 
plateau is higher by a factor of approximately 10 relative to the $\mathrm{SF}_{6}$-assisted spray and by a factor of approximately 20 relative to the ES capillary. Surprisingly, no $\mathrm{SF}_{6}$ was required for the ESH at these temperatures. No electric discharge was present in the absence of $\mathrm{SF}_{6}$ even when $V_{c}=6 \mathrm{kV}$ at $\mathrm{D}=3 \mathrm{~cm}$. The absence of electric discharge can be deduced from the mass spectra obtained.

The mass spectra obtained with $10^{-5}-\mathrm{mol} / \mathrm{L} \mathrm{BHCl}$, where $B$ is codeine are shown in Figure 3. Spectrum a was obtained with the ES capillary at room temperature, whereas spectrum $b$ is due to ESH. The difference between the two spectra is striking. ESH leads to a $\mathrm{BH}^{+}$intensity, at $m / z 300$, which is higher by a factor of 7. Furthermore, the ESH spectrum is extremely clean compared to the ES spectrum. The ES spectrum contains the $\mathrm{H}_{3} \mathrm{O}^{+}$ion, which indicates the presence of an electric discharge. Higher ES capillary potentials lead to a rapid growth of the $\mathrm{H}_{3} \mathrm{O}^{+}\left(\mathrm{H}_{2} \mathrm{O}\right)_{n}$ ions without an increase of the $\mathrm{BH}^{+}$ion [3]. The ES spectrum contains a series of ions of high intensities that correspond to $\mathrm{Na}^{+}\left(\mathrm{H}_{2} \mathrm{O}\right)_{n}$ and $\mathrm{K}^{+}\left(\mathrm{H}_{2} \mathrm{O}\right)_{n}$ as well as $\mathrm{NaB}^{+}$ and $\mathrm{KB}^{+}$. These should be due to $\mathrm{Na}^{+}$and $\mathrm{K}^{+}$salts impurities in the solution used.

The ESH spectrum lacks the discharge that indicates ions and also the $\mathrm{Na}^{+}$and $\mathrm{K}^{+}$impurity ions, even though exactly the same solution flowed through the interface in the experiments $a$ and $b$. We will call ESH spectra as observed in Figure 3b, "superclean." Superclean spectra were not the only type of spectra obtained with ESH. More often the ESH spectra did display the presence of solvent impurity ions, but at much lower relative levels than in the ES spectra, see Figure 3a. We shall call these ESH spectra the "normal" ones.

A comparison between ESH normal and superclean spectra is shown in Figure 4 and was obtained with $\mathrm{BHCl}$, where $\mathrm{B}$ is cocaine. In the normal spectrum a, the sodium impurity ions are present, whereas they are missing in the superclean spectrum $b$. The intensity of the analyte ion $\mathrm{BH}^{+}$is high in both spectra, but $\mathrm{BH}^{+}$is at an intensity higher by a factor of approximately 1.3 in the superclean spectrum. This is not a significant increase and therefore the normal spectra are almost as equally useful as superclean spectra. The normal spectra were easily obtained under ESH condition for a wide range of temperatures $\left(150-165^{\circ} \mathrm{C}\right.$ ), whereas the superclean spectra required fine tuning of the temperature over a very narrow range that could not be obtained always.

The observation of three different relative intensity ratios between solution impurity ions and analyte ions in ES, ESH normal, and ESH superclean is of interest from the standpoint of the electrospray mechanism, and its significance will be examined briefly later in this text.

Results similar to those shown in Figures 3 and 4 were obtained also for several other analytes such as the hydrochlorides of tyrosine, inosine, adenosine, and bradykinin. For all of these, the sensitivities with ESH and water as solvent were very much better than those with ES at $25^{\circ} \mathrm{C}$. The sensitivities observed with ESH and water were comparable to those abtained with ES and methanol as solvent, see Table 1 . These results demonstrate that the ESH device should be of great value in reverse-phase HPLC, where good column resolution can be obtained only with high water content $\mathrm{H}_{2} \mathrm{O}>80 \%$ solvent.

Experiments performed with water and ESH at different flow rates of the solution showed that the range of flow rates that can be handled is extremely wide. Rates from 1 to $100 \mu \mathrm{L} / \mathrm{min}$ were tested. The heat supply to the heater block and the block temperatures had to be increased as the flow rate was increased. The sensitivity for $\mathrm{BH}^{+}$obtained with a given analyte $\mathbf{B}$ was found to be approximately the same over the complete flow range.

The performance of ESH for multiply charged macromolecules such as polyprotonated proteins is also of interest. Comparison of sensitivities observed with ES at room temperature and ESH at solution temperatures near $100^{\circ} \mathrm{C}$ with water as solvent is complicated by the expected change of degree of protonation of the protein with temperature. The conversion on heating of the native more completely folded structure to a denatured more open structure with more exposed basic sites leads to a higher degree of protonation and a change of the mass spectral patterns $[14,15]$.

The residence time of the solution in the ESH capillary of $0.1 \mathrm{~mm}$ i.d. and $4.5 \mathrm{~cm}$ length at $10 \mu \mathrm{L} / \mathrm{min}$ flow rate is only $2 \mathrm{~s}$. This is much less than the 160 -s contact time used in the studies of Chait and coworkers on denaturation by heat [15]. However in the present work the solvent temperature (approximately $100{ }^{\circ} \mathrm{C}$ ), is generally higher than the temperatures used by Chait and co-workers [15] and Siu and co-workers [14]. For a protein like cytochrome $c$ whose enthalpy change for unfolding is approximately $24 \mathrm{kcal} / \mathrm{mol}$ [14], an increase of temperature from 80 to $100{ }^{\circ} \mathrm{C}$ increases the denaturation rate by a factor of approximately 6 . Therefore denaturation can not be excluded for ESH even though the contact times are short.

Because in the present work we are primarily interested in changes of sensitivity and signal stability with ESH, the mass spectra shown in Figure 5 were obtained for myoglobin that has been shown to exhibit only minor changes of protonation with temperature change [14]. Spectrum a was determined on a Sciex API III with an Ion Spray interface at $30^{\circ} \mathrm{C}$, whereas spectrum $b$ was obtained with the same instrument, but with ESH at a block temperature of $148{ }^{\circ} \mathrm{C}$. The same solution with pure water solvent was used in a and $b$. Ion spray (IS) is known to perform better than conventional ES when solutions with high water content are used [19]. Comparison of spectra a and b shows that similar sensitivities are obtained with IS and ESH. Although the highest intensity peak in ESH 
Table 1. Some representative intensities of mass-analyzed ions observed with different spray devices and solvents (with TAGA 6000E)

\begin{tabular}{|c|c|c|c|}
\hline \multirow[b]{2}{*}{ Analyte } & \multirow[b]{2}{*}{$\begin{array}{c}\mathrm{BH}^{+} \\
\text {Mass-to-Change } \\
\text { Ratio }^{\circ}\end{array}$} & \multicolumn{2}{|c|}{$\begin{array}{c}\text { Intensity }{ }^{\mathrm{a}} \\
\text { (kilocounts per second) }\end{array}$} \\
\hline & & $\begin{array}{l}\text { ES, } 25^{\circ} \mathrm{C} \\
\text { Methanol }\end{array}$ & $\begin{array}{c}\mathrm{ESH}, 157^{\circ} \mathrm{C} \\
\text { Water }\end{array}$ \\
\hline Cocaine $\mathrm{HCl}$ & 304 & 350 & 1800 \\
\hline Codeine $\mathrm{HCl}$ & 300 & 250 & 1400 \\
\hline Cytidine $\mathrm{HCl}$ & $123^{d}$ & - & 60 \\
\hline Inosine $\mathrm{HCl}$ & $137^{d}$ & 15 & 25 \\
\hline Cytochrome $c^{\circ}$ & $825^{e}$ & $\begin{array}{l}\sim 3.3^{f} \\
(15.3)^{f, g}\end{array}$ & $\begin{array}{l}\sim 2.9 \\
(13.4)^{\mathrm{g}}\end{array}$ \\
\hline
\end{tabular}

antensities of mass-analyzed ions for different spray arrangements and solvents. Intensities were not corrected for mass-dependent discrimination of the quadrupole.

Analyte at concentration of $10^{-5} \mathrm{~mol} / \mathrm{L}$ in sprayed solution.

'Mass-to-change ratio of protonated base $\mathrm{BII}^{+}$except when otherwise noted.

doubly protonated base.

'The distribution of the multiple protonation envelope indicated the presence of largely denatured cytochrome $c$ in both solvents. The maximum intensity of the protonation envelope occurred at $m / z=\sim$ 825.

$80 \%$ methanol, $20 \%$ water.

${ }^{8}$ Cytochrome $c$ sum of intensities over the complete protonation envelope.

has a three times higher intensity than the corresponding peak in the IS spectrum, the intensity distribution of the protonated peaks is different in the two spectra so that in terms of sensitivity based on the total ionization, the two methods come out quite close. The ESH spectrum is less noisy, there is much less "grass" between the peaks, and therefore it is somewhat superior to the IS spectrum.

Comparative experiments with ES and ESH were performed with denatured cytochrome $c$ on the TAGA 6000E. Two solvents were used: ES at room temperature and $80 \%$ methanol, $20 \%$ water solvent and ESH with $100 \%$ water solvent. The intensities obtained are given in Table 1. An examination of these data shows that the largest increases of sensitivity due to ESH are observed for the singly protonated bases such as cocaine and codeine. Smaller increases are observed for diprotonated bases and no increase, relative to methanol, is observed for the polyprotonated proteins. In all cases ESH provides noise-free and clean spectra.

\section{Examination Factors that Might be Responsible for the Superior Performance of ESH with Water as Solvent}

As was pointed out in the Introduction, a higher droplet temperature will lead to a faster evaporative shrinkage of the droplets and thus to a more rapid formation of the very small charged droplets that are assumed to produce the gas phase ions. With ESH the droplets when formed will be already at a temperature near the boiling point and their high temperature will be maintained by the hot flowing sheet gas. Evidence that the evaporation of the droplets obtained with ESH is much more complete was provided by the following observations. When conventional ES was used with neat water at $25{ }^{\circ} \mathrm{C}$, the counterelectrode (interface plate) was found to be wet, whereas with $\mathrm{ESH}$ this electrode was completely dry. With the conventional ES a careful off-axial positioning (see Experimental) of the spray tip relative to the interface orifice was required. When the off-axis distance was too small (less than approximately $1.5 \mathrm{~cm}$ ), the observed mass-analyzed ions were heavily clustered with solvent molecules. We attribute this to droplet penetration of the interface gas when the stream is directed close to the orifice. With the ESH no careful off-axis positioning was required. ESH was often operated in complete axial alignment and the mass spectra indicated the presence of reasonably dry interface gas.

Another factor that is probably responsible for the better performance of ESH is the change of surface tension $\gamma$ with temperature. The temperature of the aqueous solution at the tip of the capillary at optimum spray conditions, measured by placing a thermocouple in the spray, was close to the boiling point $\left(100^{\circ} \mathrm{C}\right)$. The surface tension of water decreases from $\gamma=0.073$ $\mathrm{N} \mathrm{m}^{-2}$ at $29^{\circ} \mathrm{C}$ to $0.059 \mathrm{~N} \mathrm{~m}^{-2}$ at $100^{\circ} \mathrm{C}$. From Smith's equation (eq 1), a downward shift of the ES onset potential is expected at the higher temperature:

$$
V_{\text {on }}\left(100^{\circ} \mathrm{C}\right) / V_{\text {on }}\left(20^{\circ} \mathrm{C}\right) \approx \sqrt{0.059 / 0.073}=0.91
$$

The measured onsets of spray current $I_{c}$ and mass analyzed $\mathrm{BH}^{+}$ion current are shown in Figure 6. Both currents indicate onsets at 4.3 (hot) and $4.6 \mathrm{kV}$ (cold). These onsets were corrected by subtracting the $0.65-\mathrm{kV}$ potential of the opposing electrode, that is, the interface plate; see Experimental. These values correspond to an experimental voltage ratio 0.93 that is somewhat higher than, but in line with, the effect predicted by eq 3.

Observation of the liquid cone at the capillary tip with a low power microscope revealed that the cone angle increased from a sharp angle when the aqueous solution was cold to a much wider angle when the solution was hot. The liquid retreated much closer to the capillary tip and the spray became much finer. The fine spray had the same appearance as the spray obtained with room temperature methanol, which leads to high ion intensities and a stable signal. A drop of capillary current $I_{c}$ by a factor of 3 (see Figure 2c) occurred simultaneously with the changeover to the fine water spray. We attribute this current decrease to a decrease of electric discharge. As mentioned above, the unheated water spray spectra contained electric discharge that indicates ions, whereas these ions were not present with the heated ESH spray. The decrease of the discharge should be associated with the decrease of Electrospray onset potential due to the decrease of surface tension (see eq 3 ) and the observed increase of the cone angle $\theta$. Equation 1 predicts that 

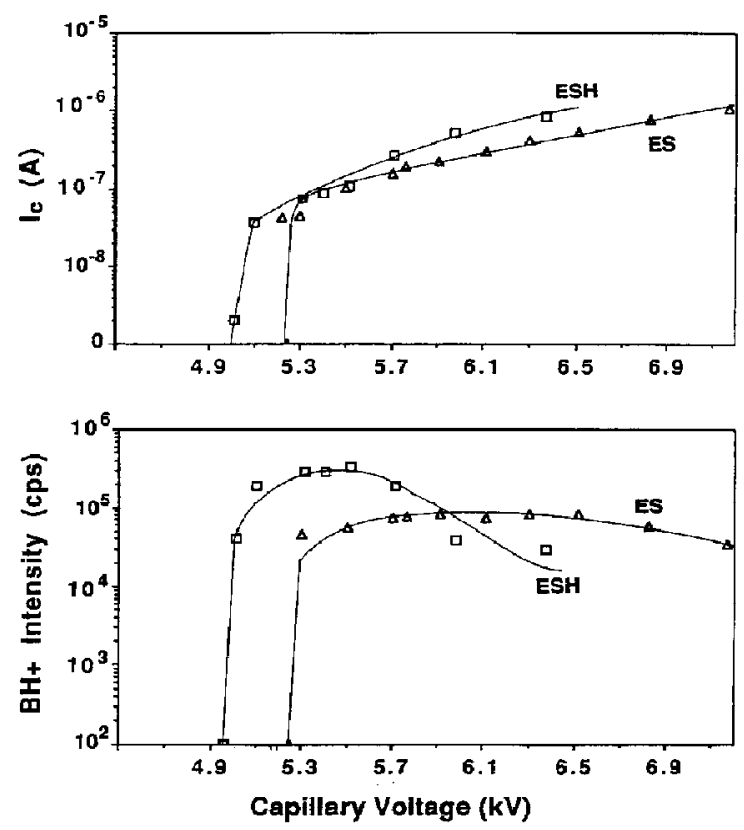

Figure 6. Plot of current $I_{c}$ due to charged droplets and gas phase ions leaving the ES capillary and the mass-analyzed analyte ion $\left(\mathrm{BH}^{+}\right)$versus capillary voltage for the conventional ES capillary at $29^{\circ} \mathrm{C}$ and the heated ES assembly at $140^{\circ} \mathrm{C}$. Current onset voltage is lower for heated ES relative to conventional ES. $[\mathrm{BHCl}]=10^{-5} \mathrm{~mol} / \mathrm{L}$, where $\mathrm{B}$ is cocaine in $100 \% \mathrm{H}_{2} \mathrm{O}$, solution flow rate at $10 \mu \mathrm{L} / \mathrm{min}$.

the field $E_{0}$ required for electrospray onset decreases as the cone angle increases. For example, an increase from $\theta=49^{\circ}$ to $\theta=80^{\circ}$ leads to a decrease of $E_{0}$ by a factor of approximately 2 .

It was discussed previously that ESH could be observed in two distinct modes, a normal mode that was easily achieved and a superclean mode that required fine tuning of the temperature. Transition from the normal to the superclean mode was attendant with an additional drop of capillary current $I_{c}$ by a factor of 3 or more, a small increase in the analyte intensity, and a nearly complete disappearance of the alkali ion peaks that are due to impurities present in the solution, see Figure 4. The spray in the superclean mode could barely be seen with the low power microscope, presumably because the emitted droplets were very much smaller.

The observation that a given ionic species-alkali ions-can be made to almost completely disappear, whereas another ionic species such as $\mathrm{BH}^{+}$is not affected is very surprising and might even be considered impossible. However, it was observed in earlier work [5] that some ion species are preferentially expressed in the ES mass spectrum. Thus protonated cocaine had a sensitivity factor that was higher by a factor of 5-10 relative to the alkali ions. This was the case for ES with methanol. The higher surface activity of protonated cocaine relative to the alkali ions was considered [5] to be a likely cause for this difference. The previous experiments [5] involved normal spray. The superclean ESH spectra are probably due to a spray with very much smaller size initial droplets. Under these conditions of extremely large surface increase, an even higher selectivity for the more surfaceactive ion species may be present and could lead to the superclean spectra. This means that the relative sensitivity factors may be dependent on the size of the droplets produced by the spray.

ESH with water works best when the temperature of the solution is close to $100{ }^{\circ} \mathrm{C}$. The dispersion into droplets in conventional ES is driven by the electric field. For ESH the dispersion could be driven partially by the electric field and partially by the temperature, that is, ESH could be a form of electro-thermospray, where droplet charging is provided by the field whereas droplet dispersion is a product of the field and the near boiling temperature.

\section{Conclusions}

The described ESH interface where the ES capillary is heated and the spray is subjected to a hot air stream that is coaxial and in the same direction as the spray, provides a greatly improved performance for solvents in which water is the major component, including $100 \%$ water. ESH works well over a wide range of flow rates, $1-100 \mu \mathrm{L} / \mathrm{min}$.

Some of the factors responsible for the enhanced performance are quite well understood. The coaxial and codirectional gas flow improves, by convection, the transport of droplets and ions to the sampling orifice. The initial high temperature of the droplets when formed and the subsequent heat transfer from the heated air stream facilitate the evaporation of water from the droplets and lead to rapid shrinkage and fission of the droplets. The near boiling point temperature of the solution at the capillary leads to a lowering of the surface tension of water and thus a lowering of the capillary voltage required for the onset of the spray. This reduces the onset potential of the electrospray and thus also the adverse effect of the electric gas discharge that is present when water is sprayed.

An increase of the Taylor cone angle, which is also observed on heating of the aqueous spray, is also expected to lead to a decrease of the voltage required for the onset of the spray.

\section{References}

1. Smith, R. D.; Loo, J. A.; Edmonds, C. G.; Barniaga, C. J.; Udseth. H. R. Anal. Chem. 1990, 62, 882.

2. Smith, D. P. H. IEEE Trans. Ind. Appl. 1986, IA-22, 527.

3. Ikonomou, M. G.; Blades, A. T.; Kebarle, P. J. Am. Soc. Mass Spectrom. 1991, 2, 497.

4. Gomez, A.; Tang, K. Physics of Fluids (in print).

5. Tang, L.; Kebarle, P. Anal. Chem. 1993, 65, 3654. Kebarle, P.; Tang, L. Anal. Chem., 1993, 65, 972A.

6. Fernandez de la Mora, J.; Rossel-Liompart, J. Proceedings of 
the 39th ASMS Conference on Mass Spectrometry and Allied Topics; Nashville, 1991; p 441.

7. Davies, C. N. In Fundamentals of Aerosol Science; Shaw, D. T., Ed.; Wiley-Interscience: Wiley, New York, 1978; $p 154$.

8. Ikonomou, M. G.; Blades, A. T.; Kebarle, P. Anal Chem. 1991, 63, 1989-1998.

9. Iribarne, J. V.; Thomson, B. A. J. Phys. Chem. 1976, 64, 2287; Thomson, B. A.; Iribarne, J. V. I. Phys. Chem. 1979, 71, 4451.

10. Schmelzeisen-Redeker, G.; Buttering, L.; Rölgen, F. W. Int. J. Mass Spectrom. Ion Processes 1989, 90, 139.

11. Wong, S. F.; Meng, C. K.; Fenn, J. B. J. Phys, Chem. 1988, 92, 546.

12. Smith, R. D.; Barniaga, C. J.; Udseth, H. R. Anal. Chem. 1988, $60,1948-52$.
13. Chowdhury, S. K.; Katta, V.; Chait, B. T. Rapid Commun. Mass Spectrom. 1990, 4, 81.

14. LeBlanc, J. C. Y.; Beauchemin, D.; Siu, K.W. M.; Guerzernont, R.: Berman, S. S. Org. Mass Spectrom. 1991, 26, 831.

15. Mirza, U. A.; Cohen, S. L.; Chait, B. T. Anal. Chem. 1993, 65, 1.

16. Lee, E. D.; Henion, J. D. Rapid Commun. Mass Spectrom. 1992, 6,727 .

17. Reid, N.; Buckley, J. A.; French, J. B.; Poon, C. C. Adv. Mass Spectrom. 1979, 8B, 1843.

18. Ikonomou, M. G; Blades, A. T.; Kebarle, P. Anal Chem. 1990, $62,957$.

19. Ikonomou, M. G.; Blades, A. T.; Kebarle, P. Anal Chem. 1991, 63, 1989. 